\title{
Late R Wave Transition by ECG Finding
}

National Cancer Institute

\section{Source}

National Cancer Institute. Late R Wave Transition by ECG Finding. NCI Thesaurus. Code C102653.

An electrocardiographic finding where the amplitude of the $\mathrm{R}$ wave does not become greater than the amplitude of the $\mathrm{S}$ wave until an unusually late point in the precordial leads, usually in leads V4 to V6. (CDISC) 